determine effects on IQ and the need for special education.

\title{
INTRACRANIAL EPENDYMOMA FOLLOW-UP STUDY
}

The management and outcome of 24 children with intracranial ependymomas ( 22 benign and well differentiated) treated over a 10-year period, 1979-1988, and with a minimum 5-year follow-up were analysed at Great Ormond Street Hospital, London, UK. Of 16 with infratentorial ependymomas, 4 were alive, all 4 having total resection and 3 having craniospinal radiotherapy in addition. Of 12 who died, 5 had total resections and 4 had radiotherapy. All 7 with incomplete resections had died within 5 years despite radiotherapy and chemotherapy as well in some. Ventriculoperitoneal shunting for hydrocephalus was required in 8 of 17 patients with posterior fossa ependymomas. In the supratentorial group of 7 patients, only one was alive and tumor-free at 5 years. No metastases were detected by myelography in 9 patients examined. (Jayawickreme DP, Hayward RD, Harkness WFJ. Intracranial ependymomas in childhood: a report of 24 cases followed for 5 years. Child's Nerv Syst July 1995;11:409-413). (Respond: Mr RD

Hayward, Department of Neurosurgery, Great Ormond Street Hospital, Great Ormond Street, London WC1 3JH, UK).

COMMENT. In posterior fossa ependymomas an apparent total resection is associated with a better outcome but may be followed by local recurrence. Partial resection carries a very poor outcome, even with radiotherapy. Supratentorial ependymomas have a worse prognosis than the infratentorial group. In general, intracranial ependymomas in childhood have a very poor prognosis. Long-term survival may be achieved only after complete resection followed by radiotherapy, with its known effects on intellectual function and school achievement. Spinal metastases are unusual and prophylactic spinal irradiation in benign ependymoma is not recommended. Multicenter studies including chemotherapy are indicated.

\section{DEVELOPMENTAL DISABILITIES}

\section{NEUROLOGICAL ASSESSMENT OF DEVELOPMENTAL DELAY}

The etiologic or diagnostic yield of the neurologic examination in 60 children referred to a pediatric neurologist for evaluation of global developmental delay was determined at the Montreal Children's HospitalMcGill University, Quebec, Canada. Examination at a mean age of 3.58 years revealed mild delay in development in 25 , moderate delay in in 23 , and severe delay in 12. EEG, MRI, metabolic screens, fragile $X$ test and karyotype established an etiologic diagnosis in 38 (63\%), including cerebral dysgenesis (17\%), HIE (10\%), chromosomal anomalies (10\%), toxins $(8 \%)$, and metabolic disorders (5\%). (Majnemer A, Shevell MI. Diagnostic yield of the neurologic assessment of the developmentally delayed child. I Pediatr August 1995;127:193199). (Reprints: Annette Majnemer PhD, Montreal Children's Hospital, 2300 Tupper St, Room A-509, Montreal, Quebec H3H 1P3, Canada).

COMMENT. Optimal management of children with developmental delay should include a neurologic examination and selected laboratory tests. An etiologic diagnosis provides physician and family with important information regarding risks of recurrence and choice of therapeutic intervention. 